\title{
Prevalence and multi-locus genotyping of Giardia duodenalis in rabbits from Shaanxi province in northwestern China
}

\author{
Huan Tang ${ }^{1,2,3}$, Yonggang $\mathrm{Ye}^{1, *}$, Runmin $\mathrm{Kang}^{1}$, Jifeng $\mathrm{Yu}^{1}$, and $\mathrm{Ye} \mathrm{Cao}^{1}$ \\ 1 Animal Breeding and Genetics Key Laboratory of Sichuan Province, Sichuan Animal Science Academy, Chengdu 610066, PR China \\ 2 College of Veterinary Medicine, Northwest A\&F University, Yangling, Shaanxi 712100, PR China \\ ${ }^{3}$ Chongqing Three Gorges Vocational College, Chongqing 404155, PR China
}

Received 11 March 2021, Accepted 11 June 2021, Published online 25 June 2021

\begin{abstract}
Giardia duodenalis is an important parasite with veterinary and public health significance worldwide. The presence and zoonotic assemblages of $G$. duodenalis have previously been reported in rabbits. In this study, to understand the infection status of $G$. duodenalis in rabbits from Shaanxi province, a total of 537 fecal samples were collected from two breeds of rabbits in four age groups (<30 days, 31-90 days, 91-200 days and $>200$ days) from four geographical origins (Fengxiang, Yangling, Tongchuan, and Shanyang). The presence of G. duodenalis in these samples was assessed using molecular assays based on beta-giardin $(b g)$. The glutamate dehydrogenase $(g d h)$ and triosephosphate isomerase (tpi) loci were then amplified in the $b g$-positive samples for multi-locus genotype (MLG) analysis. The total prevalence of $G$. duodenalis in these rabbits was $3.54 \%$ (19/537). Giardia duodenalis infection was found in both breeds of rabbits, and in all farms and age groups, but with no statistically significant differences related to these factors $(p>0.05)$. Two assemblages, including B and E, were identified, with the former the predominant assemblage detected in both breeds, and in all age groups and farms. Sequence analysis revealed 2 (named as rbg1-2), 1 (named as rtpi1), and 2 (named as rgdh1-2) haplotypes at the gene loci of $b g$, $t p i$, and $g d h$, respectively, forming a multilocus genotype (MLG) of assemblage B (rbg1, rtpi1, and rgdh1). These findings reveal the significant zoonotic potential and genetic diversity of $G$. duodenalis in rabbits in Shaanxi Province, PR China.
\end{abstract}

Key words: Giardia duodenalis, Multi-locus genotyping, Prevalence, Rabbit, Shaanxi Province.

Résumé - Prévalence et génotypage multi-locus de Giardia duodenalis chez les lapins de la province du Shaanxi, nord-ouest de la Chine. Giardia duodenalis est un parasite de grande importance vétérinaire et en santé publique dans le monde entier. La présence et les assemblages zoonotiques de G. duodenalis ont déjà été rapportés chez le lapin. Dans cette étude, pour comprendre le statut infectieux de G. duodenalis chez les lapins de la province du Shaanxi, un total de 537 échantillons fécaux ont été prélevés sur deux races de lapins dans quatre groupes d'âge $(<30$ jours, 31-90 jours, 91-200 jours et $>200$ jours) de quatre origines géographiques (Fengxiang, Yangling, Tongchuan, Shanyang). La présence de $G$. duodenalis dans ces échantillons a été évaluée à l'aide de tests moléculaires basés sur la bêta-giardine $(b g)$. Les loci de la glutamate déshydrogénase $(g d h)$ et de la triosephosphate isomérase (tpi) ont ensuite été amplifiés dans les échantillons $b g$-positifs pour l'analyse des génotypes multilocus (MLG). La prévalence totale de G. duodenalis chez ces lapins était de 3,54 \% (19/537). L'infection à Giardia duodenalis a été trouvée chez les deux races de lapins et dans tous les élevages et groupes d'âge, mais sans différence statistiquement significative liée à ces facteurs $(p>0,05)$. Deux assemblages, dont $\mathrm{B}$ et $\mathrm{E}$, ont été identifiés, le premier étant l'assemblage prédominant détecté dans les deux races, et dans tous les groupes d'âge et élevages. L'analyse des séquences a révélé des haplotypes, 2 (nommés rbg1-2), 1 (nommé rtpi1) et 2 (nommés rgdh1-2) aux loci des gènes de $b g$, tpi et $g d h$, respectivement, formant un génotype multilocus (MLG) de l'assemblage B (rbg1, rtpi1 et rgdh1). Ces résultats ont révélé l'important potentiel zoonotique et la diversité génétique de G. duodenalis chez les lapins de la province chinoise du Shaanxi.

\section{Introduction}

Giardia duodenalis is an important intestinal parasite of humans and more than 40 animal species, making it the 11th

\footnotetext{
*Corresponding author: yeyg0202@sina. com
}

most important foodborne parasite globally according to the Food and Agriculture Organization of the United Nations (FAO)/World Health Organization (WHO) [8, 18, 20, 59]. Giardiasis, caused by $G$. duodenalis, is one of most common diarrheal diseases in animals and humans, and is responsible for approximately 280 million human diarrheal cases reported 
annually worldwide $[10,15,59]$. The most common symptoms in infected individuals are foul-smelling diarrhea, greasy stools, flatulence, and bloating, and death can occur in children five years of age or younger in low-income countries [4, 6, 13, $23,28,35,36,63]$. Although asymptomatic infection has been seen in most hosts, especially animals, viable cysts of G. duodenalis excreted from these individuals can be potential transmission sources for other animals and humans through waterborne and foodborne chains [14, 26, 59].

Molecular characterization of $G$. duodenalis revealed a species complex for this parasite, and eight valid assemblages (namely A-H) have been identified [16, 44, 46-48]. Zoonotic assemblages A and B have been found in both humans and animals, and some animal-adapted assemblages (C, D, E, and F) have also been detected in humans, suggesting possible transmission between humans and animals [20, 53, 60, 64, 69].

Rabbits are an important economically farmed animal, and it is also increasingly bred as a family pet [7, 12, 54]. However, rabbits can carry zoonotic pathogens, including $G$. duodenalis $[56,65]$. The infection rate of $G$. duodenalis ranges from $1.90 \%$ to $72.30 \%[3,31,41,42,50,56,70,71]$. Three assemblages have been identified in rabbits, A, B and E, and all are potential sources of infection for humans [3, 27, 29, 41, 55, 70, 71], suggesting a potential role of rabbits in the transmission of G. duodenalis. China is the biggest rabbit meat producer around the world [38], with 849,150 tons [40]. In Shaanxi Province, rabbit breeding is increasing in prevalence, with local farms and larger agricultural companies. However, to date there have been only six reports on $G$. duodenalis infection from six Chinese provinces (Xinjiang, Heilongjiang, Liaoning, Henan, Jilin, and Shandong) [30, 41, 42, 56, 70, 71]. In this study, the prevalence and genetic diversity of $G$. duodenalis in farmed rabbits from Shaanxi province were investigated using a multilocus genotyping tool [11, 43, 67].

\section{Materials and methods}

\section{Ethics statement}

The fecal samples were collected with the farm owner's permission. All procedures of our study were reviewed and approved by the Research Ethics Committee of Northwest A\&F University, Yangling, Shaanxi.

\section{Sample collection}

A total of 537 fecal samples were collected from family farms or large-scale rabbit farms that breed approximately 1000-5000 rabbits. The selected farms are located in four geographical regions (Fengxiang, Yangling, Tongchuan, and Shanyang) in Shaanxi Province $\left(105^{\circ} 29^{\prime}-111^{\circ} 15^{\prime}\right.$ E, $31^{\circ} 42^{\prime}-$ $39^{\circ} 35^{\prime}$ N). Samples were collected in July 2017 and March 2018 (Fig. 1). All fecal samples were randomly collected from a single cage containing between one and five rabbits of the same age (<30 days, 31-90 days, 91-200 days or $>200$ days). All feces collected from a cage were considered a single sample. Each sample was placed into a clean plastic bag and marked with the date, age, and geographical origin. All fecal samples were quickly transported to the laboratory with ice packs, preserved in $2.5 \%$ potassium dichromate, and stored at $4{ }^{\circ} \mathrm{C}$ for further study.

\section{Genomic DNA extraction}

About $200 \mathrm{mg}$ of each fecal sample were washed with distilled water, as described previously [7, 58]. Next, the genomic DNA was extracted from each sample using a commercial kit, according to the manufacturer's instructions (E.Z.N.A ${ }^{\circledR}$ stool DNA kit, Omega Bio-Tek Inc., Norcross, GA, USA). All genomic DNA samples were stored at $-20{ }^{\circ} \mathrm{C}$ for further analysis.

\section{Nested PCR amplification and agarose gel electrophoresis}

To determine the prevalence of $G$. duodenalis in rabbits in Shaanxi province, all genomic DNA extracted from fecal samples was subjected to nested PCR targeting the beta giardin (bg) gene, as reported previously [8, 39]. Next, all $b g$-positive samples were subjected to nested PCR reactions targeting the gene loci of triose phosphate isomerase (tpi) and or glutamate dehydrogenase $(g d h)[39,64]$. Each PCR reaction included $15.375 \mu \mathrm{L}$ dd $\mathrm{H}_{2} \mathrm{O}, 2.5 \mu \mathrm{L} 10 \times$ Ex Taq Buffer $\left(\mathrm{Mg}^{2+}\right.$ free) (Takara Bio Inc., Dalian, PR China), $2 \mu \mathrm{L} \mathrm{MgCl}$ ( $25 \mathrm{mmol} / \mathrm{L}$ ) (Takara Bio Inc., Dalian, PR China), $2 \mu \mathrm{L}$ dNTP mixture (2.5 mmol/L) (Takara Bio Inc., Dalian, PR China), $0.125 \mu \mathrm{L}$ TaKaRa Ex Taq, $1 \mu \mathrm{L}$ forward primer, $1 \mu \mathrm{L}$ reverse primer, and $1 \mu \mathrm{L}$ DNA samples. All PCR products were detected by $1 \%$ agarose gel electrophoresis with ethidium bromide staining and visualized using a UV transilluminator (Beijing Sagecreation Technology Co., Ltd, Beijing, PR China).

\section{Sequencing and sequence analysis}

All positive PCR amplicons were sent to Sangon Biotech Co., Ltd, Shanghai, China for direct sequencing from both directions using the inner primers of nested PCRs. The obtained sequences were aligned with reference sequences downloaded from GenBank within the National Center for Biotechnology Information (NCBI) (KJ888980 for assemblage B at $b g$ loci, KY769090 for assemblage E at $b g$ loci, EU594666 for assemblage B at $g d h$ loci, and HQ666894 for assemblage B at tpi loci) (Table 2) using ClustalX 1.83. Alignments were then corrected manually. Each corrected sequence was aligned using the Basic Local Alignment Search Tool (BLAST) within NCBI to determine assemblages of $G$. duodenalis, and all corrected sequences of each gene locus were aligned with reference sequences downloaded from GenBank to investigate the genetic diversities of $G$. duodenalis isolates.

\section{Statistical analysis}

Differences in prevalence of $G$. duodenalis in rabbits from different geographical origins and age groups were analyzed using chi-squared $\left(\chi^{2}\right)$ tests within SPSS 19.0 for Windows 


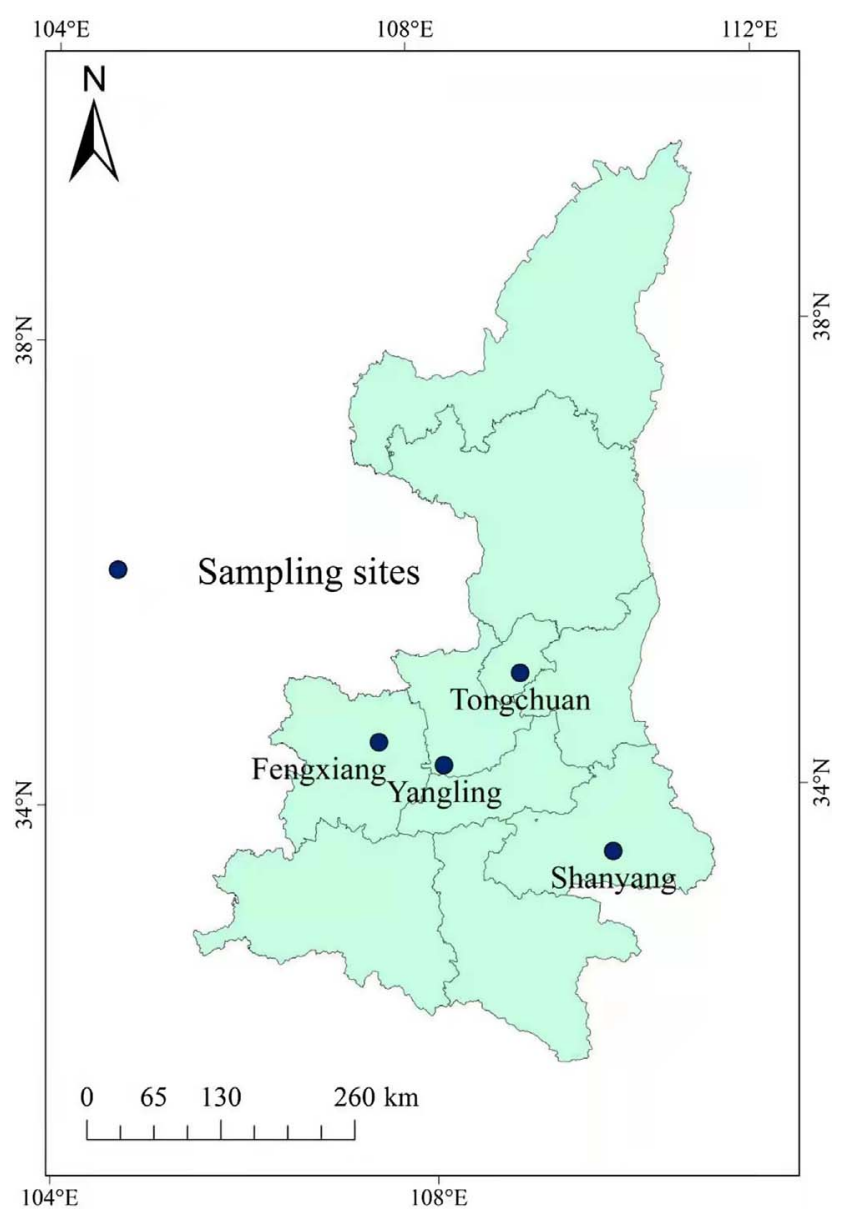

Figure 1. Sampling sites in this study.

(SPAA Inc., Chicago, IL, USA). The statistical differences were considered significant when $p<0.05$.

\section{Nucleotide sequence accession numbers}

The 19 nucleotide sequences were compared with each other and identical sequences were grouped into one. Finally, five different sequences were obtained and deposited in GenBank with the following accession numbers: MN123235 and MN123236 for the $b g$ gene, MN123234 for the tpi gene, and MN123237 and MN123238 for the $g d h$ gene.

\section{Results}

\section{Prevalence of $G$. duodenalis}

A total of 537 rabbits fecal samples from four age groups of two breeds (Rex and IRA rabbits) from five farms in four counties/cities were examined. A total of 19 rabbit fecal samples were identified as positive for $G$. duodenalis infection based on nested-PCR targeting the $b g$ gene, with a total prevalence of $3.54 \%$ (19/537). G. duodenalis was detected in both Rex $(3.68 \%)$ and IRA rabbits $(3.49 \%)$, with a slightly higher prevalence found in Rex rabbits (Table 1). All examined farms were positive for $G$. duodenalis infection, with prevalence ranging from $1.45 \%(3 / 207)$ (Farm 4 in Shanyang) to $8.43 \%(7 / 83)$ (Farm 3 in Tongchuan) (Table 1). Giardia duodenalis was detected in rabbits of all age groups, with the highest detection $(10.53 \%)$ in animals less than 30 days old, and lowest detection $(2.58 \%)$ in animals more than 200 days old (Table 1$)$. However, no significant differences in prevalence were detected among rabbits of different farms $\left(\chi^{2}=7.737, \mathrm{df}=4, p>0.05\right)$, breeds $\left(\chi^{2}=0.028, \mathrm{df}=1, p>0.05\right)$ or age groups $\left(\chi^{2}=3.970, \mathrm{df}=3\right.$, $p>0.05)$.

\section{Detecting of two assemblages}

Assemblage B and assemblage E were detected in this study. Assemblage B was identified in 18 samples (Table 2). It was detected in both Rex $(3.68 \%)$ and IRA rabbits $(3.49 \%)$, as well as on all farms and in age groups (Table 1). Assemblage E was identified in only one sample, which was collected in Rex rabbits from Fengxiang.

\section{Genetic variability examination}

At the $b g$ gene locus, two haplotypes (named rbg1, rbg2) (Table 2) were identified. BLAST search showed that the sequence of haplotype rbg1 was identical to that of $G$. duodenalis assemblage B isolates from Lemur catta (KJ888980) [32], while haplotype rbg2 exhibited high sequence identity to G. duodenalis assemblage $\mathrm{E}$ isolates from dairy cattle in China (KY769090) [66], with a nucleotide transition (C-T) at position 370 (Table 2). All $19 b g$-positive samples were analyzed by nested PCRs targeting the gene loci of tpi and $g d h$, with eight and five samples, respectively, successfully amplified for these loci. Sequence analysis showed one (named as rtpi1) and two (named rgdh1, rgdh2) (Table 2) haplotypes at the gene loci of tpi and $g d h$, respectively. The sequence of haplotype rtpil exhibited $100 \%$ identity to assemblage B isolates from rabbits in China (HQ666894) [70]. The gdh haplotypes rgdh1 and rgdh2 have one base difference with a human reference sequence from Cuba (EU594666) (Table 2) [52].

\section{Discussion}

Giardia duodenalis has been widely reported in animals worldwide, with prevalence of 1.6-91.33\% [17, 19, 20, 24, $25,68]$. In this study, a total of 19 rabbit fecal samples were identified as positive for $G$. duodenalis infection by nestedPCR targeting the $b g$ gene, for a total prevalence of $3.54 \%$ (19/537). This is in the range of prevalence for $G$. duodenalis infection, but lower than most previous studies, e.g. $8.40 \%$ in Henan [56], 7.41\% in Heilongjiang [70], 7.60\% in Europe [51], $13.79 \%$ in Jilin [30], $11.20 \%$ in Shandong [41], and $72.30 \%$ in Nigeria [3]. However, it was higher than that detected in Liaoning (1.47\%) [30] and Xinjiang (1.90\%) [71]. The different reports of $G$. duodenalis prevalence in rabbits in different studies may reflect the different examination methods used. For example, a study in European countries used coproantigen ELISA to investigate the prevalence [51], while previous studies in Heilongjiang, Henan, Jilin, and Liaoning $[30,56,70]$ used Lugol's iodine staining with microscopic 
Table 1. Prevalence of Giardia duodenalis infection in rabbits in Shaanxi Province, northwestern China.

\begin{tabular}{|c|c|c|c|c|c|}
\hline \multirow[t]{2}{*}{ Variable } & \multirow[t]{2}{*}{ Category } & \multirow[t]{2}{*}{ No. positive (\%) } & \multicolumn{3}{|c|}{ Target locus (no. positive) } \\
\hline & & & $b g$ & $g d h$ & tpi \\
\hline \multirow{3}{*}{ Breed } & Rex rabbit & $3.68(5 / 136)$ & 5 & 4 & 2 \\
\hline & IRA rabbit & $3.49(14 / 401)$ & 14 & 1 & 6 \\
\hline & Total & $3.54(19 / 537)$ & 19 & 5 & 8 \\
\hline \multirow{5}{*}{ Geographical origin } & Fengxiang & $3.68(5 / 136)$ & 5 & 4 & 4 \\
\hline & Yangling & $4.26(2 / 47)$ & 2 & 0 & 1 \\
\hline & Tongchuan & $8.43(7 / 83)$ & 7 & 1 & 2 \\
\hline & Shanyang & $1.85(5 / 271)$ & 5 & 0 & 3 \\
\hline & Total & $3.54(19 / 537)$ & 19 & 5 & 8 \\
\hline \multirow[t]{6}{*}{ Farm } & Farm1 & $3.68(5 / 136)$ & 5 & 4 & 2 \\
\hline & Farm2 & $4.26(2 / 47)$ & 2 & 0 & 1 \\
\hline & Farm3 & $8.43(7 / 83)$ & 7 & 1 & 2 \\
\hline & Farm4 & $1.45(3 / 207)$ & 3 & 0 & 2 \\
\hline & Farm5 & $3.13(2 / 64)$ & 2 & 0 & 1 \\
\hline & Total & $3.54(19 / 537)$ & 19 & 5 & 8 \\
\hline \multirow{5}{*}{ Age (days) } & $<30$ & $10.53(2 / 19)$ & 2 & 2 & 2 \\
\hline & $31-90$ & $4.35(5 / 115)$ & 5 & 0 & 3 \\
\hline & $91-200$ & $3.79(5 / 132)$ & 5 & 2 & 1 \\
\hline & $>200$ & $2.58(7 / 271)$ & 7 & 1 & 2 \\
\hline & Total & $3.54(19 / 537)$ & 19 & 5 & 8 \\
\hline \multirow[t]{3}{*}{ Assemblages } & B & 18 & 18 & 5 & 8 \\
\hline & $\mathrm{E}$ & 1 & 1 & - & - \\
\hline & Total & 19 & 19 & 5 & 8 \\
\hline \multirow[t]{2}{*}{ MLG type } & MLG B & 3 & - & - & - \\
\hline & Total & 3 & - & - & - \\
\hline
\end{tabular}

Table 2. Intra-assemblage substitutions in $b g, t p i$ and $g d h$ sequences within assemblage B and assemblage E.

\begin{tabular}{|c|c|c|c|c|c|c|}
\hline \multirow[t]{2}{*}{ Subtypes (the number of isolates) } & \multicolumn{5}{|c|}{ Nucleotide positions and substitutions } & \multirow[t]{2}{*}{ GenBank IDs } \\
\hline & 34 & 53 & 113 & 318 & 370 & \\
\hline \multicolumn{7}{|l|}{$\overline{b g}$} \\
\hline B (Ref. sequence) & $\mathrm{A}$ & $\mathrm{C}$ & $\mathrm{C}$ & G & $\mathrm{A}$ & KJ888980 \\
\hline $\operatorname{rbg} 1(n=18)$ & A & $\mathrm{C}$ & $\mathrm{C}$ & $\mathrm{G}$ & A & MN123235 \\
\hline E (Ref. sequence) & A & $\mathrm{G}$ & A & A & $\mathrm{C}$ & KY769090 \\
\hline $\operatorname{rbg} 2(n=1)$ & A & $\mathrm{G}$ & A & A & $\mathrm{T}$ & MN123236 \\
\hline \multicolumn{7}{|l|}{$g d h$} \\
\hline B (Ref. sequence) & $\mathrm{C}$ & A & $\mathrm{C}$ & $\mathrm{T}$ & $\mathrm{C}$ & EU594666 \\
\hline $\operatorname{rgdh} 1(n=4)$ & $\mathrm{C}$ & A & $\mathrm{C}$ & $\mathrm{C}$ & $\mathrm{C}$ & MN123237 \\
\hline $\operatorname{rgdh} 2(n=1)$ & $\mathrm{C}$ & A & $\mathrm{T}$ & $\mathrm{T}$ & $\mathrm{C}$ & MN123238 \\
\hline \multicolumn{7}{|l|}{ tpi } \\
\hline B (Ref. sequence) & $\mathrm{T}$ & $\mathrm{T}$ & $\mathrm{T}$ & A & $\mathrm{T}$ & HQ666894 \\
\hline rtpil $(n=8)$ & $\mathrm{T}$ & $\mathrm{T}$ & $\mathrm{T}$ & A & $\mathrm{T}$ & MN123234 \\
\hline
\end{tabular}

analysis. Microscopy analysis may underestimate prevalence, since low infection intensity may not be detected and expertise is required [50, 56, 57]. Measurements of the prevalence of G. duodenalis in rabbits from Henan (3.35\%) [56] and Xinjiang (1.90\%) [71] by PCR were both lower than the prevalence in this study. However, there may also be variation in G. duodenalis. A study from Nigeria [3] revealed a much higher prevalence $(72.30 \%)$ than in Shaanxi, potentially due to differences in livestock rearing and feeding environments. The rabbits in Nigeria were fed freshly cut forage, while the rabbits in this study received pellet feed [3]. Additionally, the rabbits studied in Nigeria were raised in close proximity to other animal species (cattle, sheep, goats, pigs, and poultry), which may increase $G$. duodenalis infection. A previous study in Shandong used the same target gene as this study to detect prevalence, with higher prevalence $(11.2 \%)$ than that detected here [41]. This difference may reflect the different breeds studied, as Long-haired and New Zealand white rabbits were studied in Shandong, but Rex and IRA rabbits were tested in Shaanxi [41]. Feeding practices may alter prevalence, with lower rates of infection in indoors rabbits $(4.57 \%)$ than in outdoors rabbits (23.08\%) in Shandong [41]. Overall, detection methods, sampling strategies, ecological and geographical environments, management practices, and husbandry modes can affect prevalence.

No significant differences in prevalence were detected among rabbits from different farms and different age groups in our study, suggesting that the infection of $G$. duodenalis in 
Table 3. Multilocus characterization of Giardia duodenalis isolates based on the $b g$, tpi and $g d h$ genes.

\begin{tabular}{lcccc}
\hline Isolate & \multicolumn{3}{c}{ Genotype or subtype } & MLG type \\
\cline { 2 - 4 } & bg & tpi & gdh \\
\hline FxA2, FxA12, TcC11 & rbg1 & rtpi1 & rgdh1 & MLG B \\
FxC30 & rbg1 & - & rgdh2 & - \\
FxE11 & rbg1 & - & rgdh1 & - \\
Sh1A90, Sh1A97, Sh2C29, TcB17, TxA18 & rbg1 & rtpi1 & - & - \\
Sh1B38, TcB8,TcB13, TcB14, TcC5, TcC29, Tx3, Tx18 & rbg1 & - & - & - \\
FxD8 & rbg2 & - & - & - \\
\hline
\end{tabular}

Shaanxi province may not be affected by these factors. A previous study conducted in Henan province, China assessed differences in prevalence among rabbits from different farms and age groups and found no significant differences $\left(\chi^{2}=\right.$ 75.79 , $\mathrm{df}=8, p<0.01$ ) among rabbits from nine farms or in different age groups $\left(\chi^{2}=5.69, \mathrm{df}=3, p>0.05\right)$ [54]. Future work should measure a greater number of samples of various rabbit breeds from more geographical origins.

Three G. duodenalis assemblages, A, B and E, were previously reported in rabbits [30, 42, 56, 70, 71]. In this study, assemblage B was identified in 18 samples and prevalent in Rex (3.68\%) and IRA rabbits (3.49\%), and on all farms and age groups (Table 1). These findings were consistent with those from studies in Nigeria and in Henan, Xinjiang, Heilongjiang, Jilin, and Liaoning provinces, China [3, 30, 42, 56, 70, 71]. Of two common assemblages (A and B) in humans, genotype AI is considered zoonotic, genotype AII is mainly found in humans, and assemblage AIII is found exclusively in animals. For assemblage B, genotypes BIII and BIV are potentially zoonotic $[9,62]$. The role of the genetic diversity of $G$. duodenalis and its clinical appearance is a controversial topic. Some reports showed that asymptomatic infection was associated with infection in children [2, 20, 29], but other reports associated clinical symptoms (being underweight, duodenal inflammation) with assemblage $\mathrm{B}$, and asymptomatic individuals of $G$. duodenalis related to assemblage A $[20,36]$. The differences may reflect genetic differences among the isolates of assemblages, the multiplication rate of parasites, the interplay with host factors, and the changes of transmission dynamics [20, 33, 37, 45, 49, 62]. Assemblage B has been detected in other animals, including beavers, cattle, dogs, horses, monkeys, muskrats, and sheep [8], and severe clinical symptoms were observed in lambs infected with $G$. duodenalis assemblage B, including malodorous and poorly formed feces and severe weight loss [5]. These findings suggest the importance of $G$. duodenalis assemblage $\mathrm{B}$ in both humans and animals. There is also evidence that assemblage E, a previously hoofed animal-specific assemblage, has zoonotic potential, since assemblage $\mathrm{E}$ has been detected in humans from some areas with poor conditions, such as Egypt and Brazil $[1,21]$. These results suggested that it is important to be aware of the potential transmission of $G$. duodenalis from rabbits to humans and other animals in Shaanxi province. Future work should increase testing by rabbit farmers to confirm the prevalence and genotypes of $G$. duodenalis.

Genetic variability has been detected within $G$. duodenalis isolates from humans and animals [20, 27]. Assemblage B was the major genotype detected, and haplotype rbg1 obtained at the $b g$ gene locus was identical to that in assemblage B isolates from rabbits, Lemur catta, and humans [54, 65]. Haplotype rbg2 has high sequence identity $(99.76 \%)$ to assemblage E isolates from dairy cattle, Tibetan sheep, foals, Capra hircus, Ovis aries, Bos Taurus, and lambs [22, 24, 31, 34, 65]. Both $\mathrm{B}$ and $\mathrm{E}$ assemblages identified in this study have been reported in humans [20]. To further examine the genetic diversity of G. duodenalis isolates from rabbits in Shaanxi Province, eight and five samples were amplified at the gene loci of tpi and $g d h$, respectively. The haplotype rtpil was identified as assemblage B-IV identical to the isolates from rabbits in China [70, 71]. The $g d h$ haplotype (rgdh1) was identical to G. duodenalis assemblage B isolates from humans in Zambia, Canada, Brazil, Poland, and water in Canada [55, 61]. Haplotypes rgdh1 and rgdh2 exhibited high sequence identity to sequences isolated from humans in Cuba [52]. Interestingly, three samples were successfully amplified at all three gene loci, forming a multilocus genotype (MLG) of assemblage B (rbg1, rtpi1, and rgdh1) (Table 3). Two were identified in rabbits aged $<30$ days from Fengxiang, and one was detected in 31-90-day-old rabbits from Tongchuan.

This study is the first report of $G$. duodenalis infection in rabbits from Shaanxi province, with a total prevalence of $3.54 \%$. Giardia duodenalis was detected in both Rex and IRA rabbits, and detected on all farms and in all age groups (Table 1). Assemblages B and E were identified in these rabbits, with the zoonotic assemblage B predominant (18 isolates) (Table 2). Genetic diversity of assemblage B isolates in rabbits was also detected. Overall, these findings suggest zoonotic potential and genetic variation of $G$. duodenalis from rabbits in Shaanxi province, and provided the basis to implement control strategies of $G$. duodenalis in this province as well as other regions of the world.

\section{Conflict of interest}

We declare that we do not have any commercial or associative interests that represent a conflict of interest in connection with the work submitted.

\section{References}

1. Abdel-Moein KA, Saeed H. 2016. The zoonotic potential of Giardia intestinalis assemblage E in rural settings. Parasitology Research, 115(8), 3197-3202.

2. Ahmad AA, El-Kady AM, Hassan TM. 2020. Genotyping of Giardia duodenalis in children in upper Egypt using assemblage- specific PCR technique. PLoS One, 15, e0240119. 
3. Akinkuotu OA, Greenwood SJ, McClure J, Takeet MI, Otesile EB, Olufemi F. 2018. Multilocus genotyping of Giardia duodenalis infecting rabbits in Ogun State, Nigeria. Veterinary Parasitology Regional Studies Reports, 13, 171-176.

4. Allain T, Buret AG. 2020. Pathogenesis and post-infectious complications in giardiasis. Advances in Parasitology, 107, 173-199.

5. Aloisio F, Filippini G, Antenucci P, Lepri E, Pezzotti G, Cacciò SM, Pozio E. 2006. Severe weight loss in lambs infected with Giardia duodenalis assemblage B. Veterinary Parasitology, 142 (1-2), 154-158.

6. Bartelt LA, Platts-Mills JA. 2016. Giardia: A pathogen or commensal for children in high-prevalence settings? Current Opinion in Infectious Diseases, 29, 502-507.

7. Bradbury AG, Dickens GJ. 2016. Appropriate handling of pet rabbits: a literature review. Journal of Small Animal Practice, 57, 503-509.

8. Caccio SM, Lalle M, Svard SG. 2018. Host specificity in the Giardia duodenalis species complex. Infection, Genetics and Evolution, 66, 335-345.

9. Caccio SM, Ryan U. 2008. Molecular epidemiology of giardiasis. Molecular and Biochemical Parasitology, 160(2), $75-80$.

10. Cernikova L, Faso C, Hehl AB. 2018. Five facts about Giardia lamblia. PLoS Pathogens, 14.

11. Chen D, Zou Y, Li Z, Wang SS, Xie S, Shi LQ, Zou FC, Yang J, Zhao GH, Zhu XQ. 2019. Occurrence and multilocus genotyping of Giardia duodenalis in black-boned sheep and goats in southwestern China. Parasites \& Vectors, 12, 102.

12. Cullere M, Dalle ZA. 2018. Rabbit meat production and consumption: State of knowledge and future perspectives. Meat Science, 143, 137-146.

13. Dixon BR. 2021. Giardia duodenalis in humans and animals Transmission and disease. Research in Veterinary Science, 135, 283-289.

14. Efstratiou A, Ongerth JE, Karanis P. 2017. Waterborne transmission of protozoan parasites: Review of worldwide outbreaks - An update 2011-2016. Water Research, 114, 14-22.

15. Einarsson E, Ma'ayeh S, Svard SG. 2016. An up-date on Giardia and giardiasis. Current Opinion in Microbiology, 34, 47-52.

16. Ey PL, Mansouri M, Kulda J, Nohýnková E, Monis PT, Andrews RH, Mayrhofer G. 1997. Genetic analysis of Giardia from hoofed farm animals reveals artiodactyl-specific and potentially zoonotic genotypes. Journal of Eukaryotic Microbiology, 44(6), 626-635.

17. Faridi A, Tavakoli K, Sadooghian S, Firouzeh N. 2020. Frequency of different genotypes of Giardia duodenalis in slaughtered sheep and goat in east of iran. Journal of Parasitic Diseases, 44, 618-624.

18. FAO/WHO. 2014. Multicriteria-based ranking for risk management of food-borne parasites. Available at: http://www.who.int/ iris/handle/10665/112672. Accessed 1 June 2015.

19. Fazaeli A, Kohansal MH, Spotin A, Haniloo A, Nourian A, Khiabani A, Siyadatpanah A, Norouzi R, Nissapatorn V. 2021. Infection rate and genetic diversity of Giardia duodenalis assemblage $\mathrm{C}$ in Iranian stray dogs, targeting the glutamate dehydrogenase gene. Veterinary World, 14, 419-425.

20. Feng Y, Xiao L. 2011. Zoonotic potential and molecular epidemiology of Giardia species and giardiasis. Clinical Microbiology Reviews, 24, 110-140.

21. Foronda P, Bargues MD, Abreu-Acosta N, Periago MV, Valero MA, Valladares B, Mas-Coma S. 2008. Identification of genotypes of Giardia intestinalis of human isolates in Egypt. Parasitology Research, 103(5), 1177-1181.

22. Geurden T, Thomas P, Casaert S, Vercruysse J, Claerebout E. 2008. Prevalence and molecular characterisation of Cryptosporidium and Giardia in lambs and goat kids in Belgium. Veterinary Parasitology, 155, 142-145.

23. Geurden T, Vercruysse J, Claerebout E. 2010. Is Giardia a significant pathogen in production animals? Experimental Parasitology, 124, 98-106.

24. Gomez-Munoz MT, Navarro C, Garijo-Toledo MM, Dea-Ayuela MA, Fernandez-Barredo S, Perez-Gracia MT, DominguezMarquez MV, Borras R. 2009. Occurrence and genotypes of Giardia isolated from lambs in Spain. Parasitology International, 58, 297-299.

25. Guo Y, Li N, Feng Y, Xiao L. 2021. Zoonotic parasites in farmed exotic animals in China: Implications to public health. International Journal for Parasitology: Parasites and Wildlife, $14,241-247$

26. Hamilton KA, Waso M, Reyneke B, Saeidi N, Levine A, Lalancette C, Besner MC, Khan W, Ahmed W. 2018. Cryptosporidium and Giardia in wastewater and surface water environments. Journal of Environmental Quality, 47, 10061023.

27. Heyworth MF. 2016. Giardia duodenalis genetic assemblages and hosts. Parasite, 23, 13.

28. Horton B, Bridle H, Alexander CL, Katzer F. 2019. Giardia duodenalis in the UK: current knowledge of risk factors and public health implications. Parasitology, 146, 413424.

29. Ignatius R, Gahutu JB, Klotz C, Steininger C, Shyirambere C, Lyng M, Musemakweri A, Aebischer T, Martus P, Harms G, Mockenhaupt FP. 2012. High prevalence of Giardia duodenalis Assemblage B infection and association with underweight in Rwandan children. PLOS Neglected Tropical Diseases, 6(6), e1677.

30. Jiang J, Ma JG, Zhang NZ, Xu P, Hou G, Zhao Q, Zhang XX. 2018. Prevalence and risk factors of Giardia duodenalis in domestic rabbbits (Oryctolagus cuniculus) in Jilin and Liaoning province, northeastern China. Journal of Infection and Public Health, 11, 723-726.

31. Jin Y, Fei J, Cai J, Wang X, Li N, Guo Y, Feng Y, Xiao L. 2017. Multilocus genotyping of Giardia duodenalis in Tibetan sheep and yaks in Qinghai, China. Veterinary Parasitology, 247, 70-76.

32. Karim MR, Wang R, Yu F, Li T, Dong H, Li D, Zhang L, Li J, Jian F, Zhang S, Rume FI, Ning C, Xiao L. 2015. Multi-locus analysis of Giardia duodenalis from nonhuman primates kept in zoos in China: geographical segregation and host-adaptation of assemblage B isolates. Infection, Genetics and Evolution, 30, $82-88$.

33. Kasaei R, Carmena D, Jelowdar A, Beiromvand M. 2018. Molecular genotyping of Giardia duodenalis in children from Behbahan, southwestern Iran. Parasitology Research, 117, $1425-1431$.

34. Kostopoulou D, Casaert S, Tzanidakis N, van Doorn D, Demeler J, von Samson-Himmelstjerna G, Saratsis A, Voutzourakis N, Ehsan A, Doornaert T, Looijen M, De Wilde N, Sotiraki S, Claerebout E, Geurden T. 2015. The occurrence and genetic characterization of Cryptosporidium and Giardia species in foals in Belgium, The Netherlands, Germany and Greece. Veterinary Parasitology, 211, 170-174.

35. Lanata CF, Fischer-Walker CL, Olascoaga AC, Torres CX, Aryee MJ, Black RE, Child Health Epidemiology Reference Group of the World Health, O, Unicef. 2013. Global causes of 
diarrheal disease mortality in children $<5$ years of age: a systematic review. PLoS One, 8, e72788.

36. Lebbad M, Petersson I, Karlsson L, Botero-Kleiven S, Andersson JO, Svenungsson B, Svard SG. 2011. Multilocus genotyping of human Giardia isolates suggests limited zoonotic transmission and association between assemblage B and flatulence in children. PLoS Neglected Tropical Diseases, 5(8), e1262.

37. Lecova L, Tumova P, Nohynkova E. 2019. Clone-based haplotyping of Giardia intestinalis assemblage B human isolates. Parasitology Research, 118(1), 355-361.

38. Li DY, Cao FF, Qin YH. 2018. Current situation and prospect of rabbit industry in Northwest China. Chinese Journal of Rabbit Farming, 06, 18-20 [In Chinese].

39. Li J, Wang Z, Karim MR, Zhang L. 2020. Detection of human intestinal protozoan parasites in vegetables and fruits: a review. Parasites \& Vectors, 13, 380 .

40. Li S, Zeng W, Li R, Hoffman LC, He Z, Sun Q, Li H. 2018. Rabbit meat production and processing in China. Meat Science, 145, 320-328.

41. Li TS, Zou Y, Peng JJ, Wang LQ, Zhang HS, Cong W, Zhu XQ, Sun XL. 2020b. Prevalence and genotype distribution of Giardia duodenalis in rabbits in Shandong Province. Eastern China. Biomed Research International, 2020, 4714735.

42. Liu A, Yang F, Shen Y, Zhang W, Wang R, Zhao W, Zhang L, Ling H, Cao J. 2014. Genetic analysis of the Gdh and Bg genes of animal-derived Giardia duodenalis isolates in Northeastern China and evaluation of zoonotic transmission potential. PLoS One, 9, e95291.

43. Ma X, Wang Y, Zhang HJ, Wu HX, Zhao GH. 2018. First report of Giardia duodenalis infection in bamboo rats. Parasites \& Vectors, 11(1), 520.

44. Mayrhofer G, Andrews RH, Ey PL, Chilton NB. 1995. Division of Giardia isolates from humans into two genetically distinct assemblages by electrophoretic analysis of enzymes encoded at 27 loci and comparison with Giardia muris. Parasitology, 111 (Pt 1), 11-17.

45. Mbae C, Mulinge E, Guleid F, Wainaina J, Waruru A, Njiru ZK, Kariuki S. 2016. Molecular characterization of Giardia duodenalis in children in Kenya. BMC Infectious Diseases, 16, 126.

46. Monis PT, Andrews RH, Mayrhofer G, Ey PL. 1999. Molecular systematics of the parasitic protozoan Giardia intestinalis. Molecular Biology and Evolution, 16(9), 1135-1144.

47. Monis PT, Andrews RH, Mayrhofer G, Ey PL. 2003. Genetic diversity within the morphological species Giardia intestinalis and its relationship to host origin. Infection, Genetics and Evolution, 3(1), 29-38.

48. Monis PT, Andrews RH, Mayrhofer G, Mackrill J, Kulda J, Isaac-Renton JL. 1998. Novel lineages of Giardia intestinalis identified by genetic analysis of organisms isolated from dogs in Australia. Parasitology, 116(1), 7-19.

49. Naz A, Nawaz Z, Rasool MH, Zahoor MA. 2018. Cross-sectional epidemiological investigations of Giardia lamblia in children in Pakistan. Sao Paulo Medical Journal, 136(5), 449-453.

50. Ortega-Pierres MG, Jex AR, Ansell BRE, Svard SG. 2018. Recent advances in the genomic and molecular biology of Giardia. Acta Tropica, 184, 67-72.

51. Pantchev N, Broglia A, Paoletti B, Globokar VM, Bertram A, Nockler K, Caccio SM. 2014. Occurrence and molecular typing of Giardia isolates in pet rabbits, chinchillas, guinea pigs and ferrets collected in Europe during 2006-2012. Veterinary Record, 175, 18.

52. Pelayo L, Nunez FA, Rojas L, Furuseth HE, Gjerde B, Wilke H, Mulder B, Robertson L. 2008. Giardia infections in Cuban children: the genotypes circulating in a rural population. Annals of Tropical Medicine and Parasitology, 102(7), 585-595.
53. Pipikova J, Papajova I, Majlathova V, Soltys J, Bystrianska J, Schusterova I, Vargova V. 2020. First report on Giardia duodenalis assemblage $\mathrm{F}$ in Slovakian children living in poor environmental conditions. Journal of Microbiology, Immunology and Infection, 53, 148-156.

54. Prebble JL, Shaw DJ, Meredith AL. 2015. Bodyweight and body condition score in rabbits on four different feeding regimes. Journal of Small Animal Practice, 56, 207-212.

55. Prystajecky N, Tsui CK, Hsiao WW, Uyaguari-Diaz MI, Ho J, Tang P, Isaac-Renton J. 2015. Giardia spp. are commonly found in mixed assemblages in surface water, as revealed by molecular and whole-genome characterization. Applied and Environmental Microbiology, 81(14), 4827-4834.

56. Qi M, Xi J, Li J, Wang H, Ning C, Zhang L. 2015. Prevalence of zoonotic Giardia duodenalis Assemblage B and first identification of Assemblage $\mathrm{E}$ in rabbit fecal samples isolates from Central China. Journal Eukaryotic Microbiology, 62, 810-814.

57. Rousseau A, La Carbona S, Dumètre A, Robertson LJ, Gargala G, Escotte-Binet S, Favennec L, Villena I, Gérard C, Aubert D. 2018. Assessing viability and infectivity of foodborne and waterborne stages (cysts/oocysts) of Giardia duodenalis, Cryptosporidium spp., and Toxoplasma gondii: a review of methods. Parasite, 25, 14.

58. Ryan U, Caccio SM. 2013. Zoonotic potential of Giardia. International Journal for Parasitology, 43(12-13), 943-956.

59. Ryan U, Hijjawi N, Feng Y, Xiao L. 2019. Giardia: an underreported foodborne parasite. International Journal for Parasitology, 49(1), 1-11.

60. Soliman RH, Fuentes I, Rubio JM. 2011. Identification of a novel Assemblage B subgenotype and a zoonotic Assemblage C in human isolates of Giardia intestinalis in Egypt. Parasitology International, 60, 507-511.

61. Souza SL, Gennari SM, Richtzenhain LJ, Pena HF, Funada MR, Cortez A, Gregori F, Soares RM. 2007. Molecular identification of Giardia duodenalis isolates from humans, dogs, cats and cattle from the state of Sao Paulo, Brazil, by sequence analysis of fragments of glutamate dehydrogenase (gdh) coding gene. Veterinary Parasitolgy, 149, 258-264.

62. Sprong H, Caccio SM, van der Giessen JW, Zoopnet Network Partners. 2009. Identification of zoonotic genotypes of Giardia duodenalis. PLoS Neglected Tropical Diseases, 3(12), e558.

63. Squire SA, Ryan U. 2017. Cryptosporidium and Giardia in Africa: current and future challenges. Parasites \& Vectors, 10, 195.

64. Villamizar X, Higuera A, Herrera G, Vasquez AL, Buitron L, Munoz LM, Gonzalez CF, Lopez MC, Giraldo JC, Ramirez JD. 2019. Molecular and descriptive epidemiology of intestinal protozoan parasites of children and their pets in Cauca, Colombia: a cross-sectional study. BMC Infectious Diseases, 19, 190.

65. Wang L, Xiao L, Duan L, Ye J, Guo Y, Guo M, Liu L, Feng Y. 2013. Concurrent infections of Giardia duodenalis, Enterocytozoon bieneusi, and Clostridium difficile in children during a cryptosporidiosis outbreak in a pediatric hospital in China. PLOS Neglected Tropical Diseases, 7, e2437.

66. Wang X, Cai M, Jiang W, Wang Y, Jin Y, Li N, Guo Y, Feng Y, Xiao L. 2017. High genetic diversity of Giardia duodenalis assemblage $\mathrm{E}$ in pre-weaned dairy calves in Shanghai, China, revealed by multilocus genotyping. Parasitology Research, 116, 2101-2110.

67. Xie SC, Zou Y, Chen D, Jiang MM, Yuan XD, Li Z, Zou FC, Yang JF, Sheng JL, Zhu XQ. 2018. Occurrence and multilocus genotyping of Giardia duodenalis in Yunnan Black Goats in China. Biomed Research International, 2018, 4601737.

68. Yin YL, Zhang HJ, Yuan YJ, Tang H, Chen D, Jing S, Wu HX, Wang SS, Zhao GH. 2018. Prevalence and multi-locus 
genotyping of Giardia duodenalis from goats in Shaanxi province, northwestern China. Acta Tropica, 182, 202-206.

69. Zahedi A, Field D, Ryan U. 2017. Molecular typing of Giardia duodenalis in humans in Queensland - first report of Assemblage E. Parasitology, 1154-1161.

70. Zhang W, Shen Y, Wang R, Liu A, Ling H, Li Y, Cao J, Zhang X, Shu J, Zhang L. 2012. Cryptosporidium cuniculus and
Giardia duodenalis in rabbits: genetic diversity and possible zoonotic transmission. PLoS One, 7, e31262.

71. Zhang X, Qi M, Jing B, Yu F, Wu Y, Chang Y, Zhao A, Wei Z, Dong H, Zhang L. 2018. Molecular characterization of Cryptosporidium spp., Giardia duodenalis, and Enterocytozoon bieneusi in rabbits in Xinjiang. China. Journal of Eukaryotic Microbiology, 65, 854-859.

Cite this article as: Tang H, Ye Y, Kang R, Yu J \& Cao Y. 2021. Prevalence and multi-locus genotyping of Giardia duodenalis in rabbits from Shaanxi province in northwestern China. Parasite 28, 54.

\section{PARASTE}

An international open-access, peer-reviewed, online journal publishing high quality papers on all aspects of human and animal parasitology

Reviews, articles and short notes may be submitted. Fields include, but are not limited to: general, medical and veterinary parasitology; morphology, including ultrastructure; parasite systematics, including entomology, acarology, helminthology and protistology, and molecular analyses; molecular biology and biochemistry; immunology of parasitic diseases; host-parasite relationships; ecology and life history of parasites; epidemiology; therapeutics; new diagnostic tools.

All papers in Parasite are published in English. Manuscripts should have a broad interest and must not have been published or submitted elsewhere. No limit is imposed on the length of manuscripts.

Parasite (open-access) continues Parasite (print and online editions, 1994-2012) and Annales de Parasitologie Humaine et Comparée (1923-1993) and is the official journal of the Société Française de Parasitologie. 